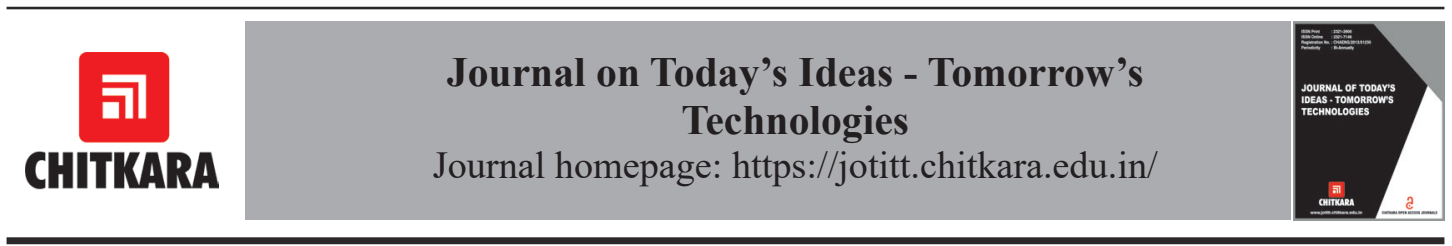

\title{
Plantation and Harvesting Autonomous Locomotive (PHAL)
}

\author{
${ }^{1}$ Aditya Garg and ${ }^{2}$ Chaitanya Rao* \\ ${ }^{1}$ Deenbandhu Chhoturam University, Murthal, Sonepat, Haryana-131039, India \\ ${ }^{2}$ Chitkara University Institute of Engineering \& Technology, Chitkara University, Punjab-140401, India \\ Email: chaitanyarao76@gmail.com*
}

\section{ARTICLE INFORMATION}

Received: June 13, 2020

Revised: June 26, 2020

Accepted: June 28, 2020

Published online: December 03, 2020

Keywords:

Agriculture, Autonomous, Green technology, Low cost

\begin{abstract}
Agriculture has seen quite a good growth due to the latest machinery being used to maximize yield and minimize cost. People around the world are starting to understand the inherent potential and scope of automation and robotics in agriculture. However, there are many problems which continue to prevail like the non-availability of labour, poor and costly machinery, etc. So there is a need to address these existing problems. This project addresses the inherent difficulties in the agricultural field. It tries to provide a remarkable solution to many of the existing problems. This project, named PHAL is a rover type bot which can perform all the basic activities included in farming. It is fully autonomous, ecofriendly machine which can perform many tasks like ploughing, sowing, irrigation, harvesting etc. Using this machine, farmers can get rid of majority of the problems, all this at a very low cost.
\end{abstract}

DOI: $10.15415 /$ jotitt.2020.81004

\section{Introduction}

India is agriculture dependent nation. As per 2018 data, agriculture employed more than 50\% of the India workforce and contributed $17-18 \%$ to country's GDP [1]. Fig. 1. is a chart signifying the importance of agriculture industry in Indian economy [2]. It shows year wise contribution of agriculture to country's GDP in Billion INR.

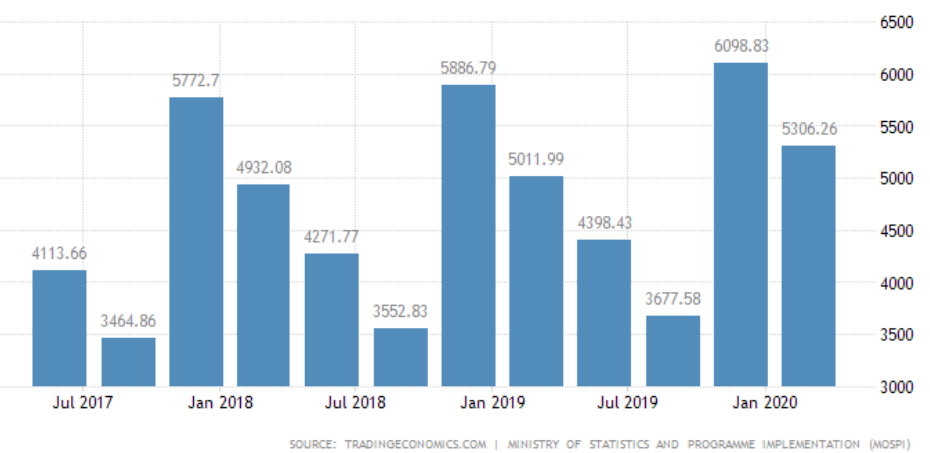

Figure 1: Contribution of Agricultural sector in India's GDP [2]

The Author(s) 2020. This article is published with open access at https://jotitt.chitkara.edu.in. ISSN No.: 2321-3906 (Print) ISSN No.: 2321-7146 (Online) Registration No. : CHAENG/2013/51235 
The year 2020 has proven to be a disaster to all types of industries around the globe. The agriculture industry is also one of them. As one can see from the above chart, GDP from Agriculture in India decreased to INR 5306.26 Billion in the first quarter of 2020 from INR 6098.83 Billion in the fourth quarter of 2019. Due to the COVID-19 pandemic, farmers are facing a huge scarcity of labour. The labour has migrated to their homes due to the nationwide lockdown and so majority of the farmers are unable to take care of their farms and crops. This can result in wastage of the crops and can significantly affect the farmers. If the crops are not taken care of, it may result in scarcity of food which can prove to be very disastrous not only for farmers but for the whole nation. So, it becomes necessary to find solutions to help farmers in best possible ways. There is a startup, named GRoboMac in Bengaluru which has tried addressing the issue of farms automation. However, their solution performs limited operations (like only harvesting) and is only suitable for only some crops like cotton and strawberry [3].

If we talk about non-autonomous machinery such as high-tech tractors that are available in the farming sector, not all farmers can afford them. Not only their initial cost is high, but their maintenance cost is high too. In addition, most of these machineries use petroleum as fuel that certainly has negative impact on the environment.

Our solution PHAL is totally different from the existing solutions available in the agriculture sector today. It can perform majority of the operations that farmers encounter. It can perform ploughing, sowing, irrigation, harvesting etc. and that too with most of the crops. It is low in cost, highly user friendly and hence it is easy to operate. It uses GPS technology to mark the working area and automatically decides its treading path using an Occupancy Grid Mapping Algorithm. The main feature of it is that it uses LASER for harvesting instead of conventional rotating drum mechanism. It is electrically powered and does not use petrol/diesel for energy. Hence there are no harmful emissions in the environment and the cost of fuel is saved. Also, the PHAL has a solar powered mechanism thus promoting green and sustainable energy. It can be remotely accessed using a smartphone and all its operations can be controlled using smartphone app. Thus, there is no need for any attendant to be present at every instant with PHAL. Not only does it perform the basic agriculture operations, it has the latest technology for various soil sensing needs, like moisture sensing and it gives information about weather directly on the app.

\section{Methodology}

The working of PHAL can be understood by four different levels (as shown in Fig. 2).

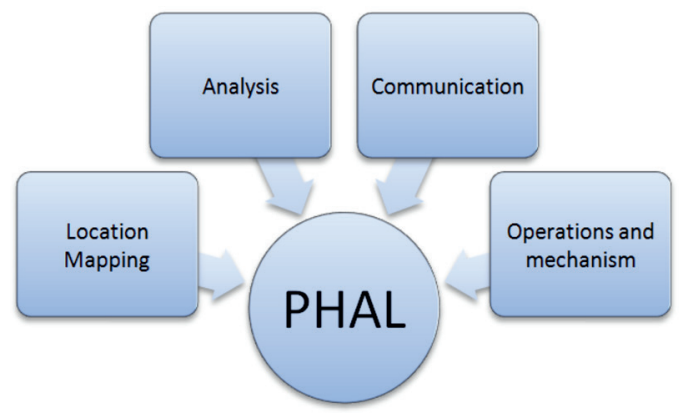

Figure 2: Working of PHAL

\subsection{Location Mapping}

Location is key element of any farming operation. The rover cannot start to work if it does not know where to work upon. Hence the rover should know which land to work on. For this purpose, PHAL includes location mapping, i.e. specifying the area to the rover to work on.

\subsubsection{Working}

The location mapping works on the basis of GPS (Global Positioning system) module which is enabled using Arduino microcontroller. The GPS of the rover is used to show the location using an application on the farmer's smartphone that will then ask him to mark the field area to work upon. The four corner coordinates are then 
relayed to the rover using Amazon Web Services. Arduino MKR microcontroller will work upon these coordinates and make a virtual grid using the Occupancy Grid Mapping Algorithm [4]. So, this provides a path for rover to tread upon. This is a one time setup task so the user does not have to worry about it later (though it can be done any number of times as per requirement).

\subsection{Analysis}

Analysis is another key component that a farmer has and usually a machine don't. This product has solved the problem by bringing machine learning into the picture. The rover is capable of analyzing the soil. The main purpose to bring the analysis in the picture is to yield more crops and more efficiently with a better health. The rover would be capable of analyzing parameters like -

(i) Water content

(ii) Soil temperature

(iii) Atmospheric humidity

(iv) Contents of the soil

(v) Analysis for weeds and sorting using machine learning

There are various components and sensors required for this like Arduino, DHT22 sensor, Soil composition sensors, Pixy 2 or Openmv M7 module etc.

\subsection{Operation}

The technology employed for harvesting purpose is based on LASER cutting. A laser in front of the rover is attached with the collecting drum. When the rover moves forward, the laser comes in contact with the crop and thereby cutting it. The drum at the back of laser collects the harvested crop. For ploughing, there is a ploughing tool attached at the bottom of rover. The irrigation and delivering of pesticides etc. is done using nozzles at the bottom of the rover.

\subsection{Communication}

The main aspect in this project is controlling of rover using commands given by the app, transmission of analysis report and also the mapping information from user to the rover. The rover is to be enabled with an inbuilt WiFi hotspot and then using AWS it can send notifications and analysis reports to the user directly on the app. Some of the components required in it are Arduino MKR 1000/ Raspberry $\mathrm{Pi}$ with a Wi-Fi shield, Inbuilt Wi-Fi hotspot module and AWS.

\section{Results and Discussion}

The key progress and up-gradation of such a product depends directly on a battery, solar power and communication technology. As most of these technologies have a vast scope of improvement, so these can help improve the performance and ability of the forthcoming versions. An important question would be related to the size of the rover. Through a relative calculation, it is claimed that PHAL would be of the size of 3/4 of a king-size bed. Such an enormous size machine has its own pros and cons. The most prominent con would be the handling, but since it is autonomous, handling it won't be an issue. The pros of a bigger structure are of the increased surface area for the solar energy harvesting alongside being able to store a larger amount of seed and water for sowing and irrigation respectively. Also, it is notable throughout the discussion, there are still many tasks PHAL is incapable of performing considering the current design and progress such as weeding. Such a purpose can be achieved by reducing the size of the PHAL since such a gigantic machine may crush the underlying crop as well. From the view of economics, the calculated cost of PHAL would be around INR 275000-325000 (approx.). This makes it easily viable to most of the farmers as the capital cost is less, (even lesser than the cost the farmer has to pay to 4 men for a year). Lastly, everything boils down to efficiency and productivity relative to that of labour working on the farm. Since a machine is definitely capable to eradicate the human factors like rest and inactivity and boost the daily productivity meter, the rover can prove to be a very big leap in the sense of productivity and efficiency. 


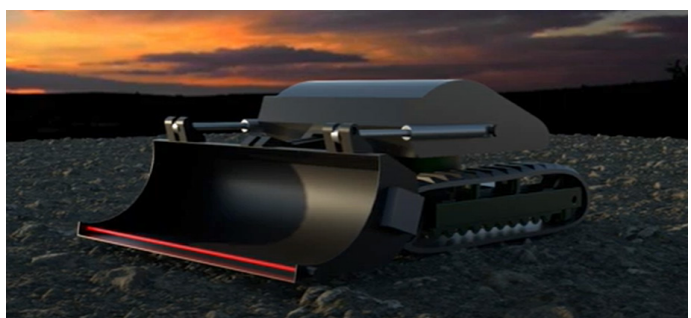

Figure 3: Depiction of PHAL

PHAL is optimistic and can prove to be revolutionary with respect to the current scenario of the agriculture sector in India. A big set of problems can be vanquished by the use of such intricate technologies put together to form a single product. The way the project design looks like in a virtual atmosphere is depicted in Fig. 3.

\section{Conclusion}

The PHAL is a remarkable solution for the existing problems prevailing in the agricultural sector. It is a remarkable combination of conventional farming with modern technology. It can help farmers all around the globe to maximize profit and minimize cost and manual hard work. It has an infinite scope as food, which is produced by agriculture, is a basic need we would still require it irrespective of the development we humans would achieve.

\section{References}

[1] Wikipedia. Agriculture in India. 2020.[Online] Available: https://en.wikipedia.org/wiki/ Agriculture_in_India\#: :text $=\mathrm{As} \% 20$ per $\% 202018 \% 2 \mathrm{C} \% 20$ agriculture $\% 20$ employed,of\%20 the \%20workforce $\% 20$ in\%202014 [Accessed: June 2020]

[2] Trading Economics. Statistics of contribution of agricultural sector in India's GDP over past years. 2020. [Online] Available: https:// tradingeconomics.com/india/gdp-fromagriculture [Accessed: June 2020]

[3] S. Sharma. This Bengaluru techie-turnedfarmer has made India's first agri-tech robot to battle farm labour shortage. 2017. [Online] Available: https://factordaily. comagritech-cotton-picking-robotindia/[Accessed: June 2020]

[4] Wikipedia. Occupancy grid mapping algorithm for location mapping. 2020. [Online ] Available: https://en.wikipedia.org/wiki/Occupancy_ grid_mapping [Accessed: June 2020].

This article has been published as a part of Special regular issue of Journal on Today's Ideas Tomorrow's Technologies. Most of the articles in this issue are the papers for which the original ideas were presented at NOVATE 2020 (https://www.chitkara.edu.in/novate), a competition organized by Chitkara University and supported by Ministry of Electronics and Information Technology, Govt. Of India, Institution's Innovation Council, NSTEDB, Govt. Of India and FICCI. Student participants have written most of these articles. Some basic editing work has been done at the editorial level, but same have not been corrected very rigorously so as to preserve basic touch of student's writing.

\section{司 CHITKARA Journal on Today's Ideas - Tomorrow's Technologies Chitkara University, Saraswati Kendra, SCO 160-161, Sector 9-C, Chandigarh, 160009, India}

Volume -8, Issue-1

June 2020

ISSN 2321-3906

Copyright: [C 2020 Aditya Garg and Chaitanya Rao] This is an Open Access article published in Journal on Today's Ideas - Tomorrow's Technologies by Chitkara University Publications. It is published with a Creative Commons Attribution- CC-BY 4.0 International License. This license permits unrestricted use, distribution, and reproduction in any medium, provided the original author and source are credited. 